\title{
Dynamic Olley-Pakes Productivity Decomposition with Entry and Exit
}

\section{Citation}

Melitz, Marc J., and Sašo Polanec. 2015. “Dynamic Olley-Pakes Productivity Decomposition with Entry and Exit." The RAND Journal of Economics 46 (2) (April 23): 362-375. doi:10.1111/1756-2171.12088.

\section{Published Version}

10.1111/1756-2171.12088

\section{Permanent link}

http://nrs.harvard.edu/urn-3:HUL.InstRepos:17492204

\section{Terms of Use}

This article was downloaded from Harvard University's DASH repository, and is made available under the terms and conditions applicable to Open Access Policy Articles, as set forth at http:// nrs.harvard.edu/urn-3:HUL.InstRepos:dash.current.terms-of-use\#OAP

\section{Share Your Story}

The Harvard community has made this article openly available.

Please share how this access benefits you. Submit a story.

\section{Accessibility}




\title{
Dynamic Olley-Pakes Productivity Decomposition with Entry and Exit*
}

\author{
Marc J. Melitz ${ }^{\dagger}$ \\ Harvard University, NBER and CEPR
}

\author{
Sašo Polanec ${ }^{\ddagger}$ \\ University of Ljubljana
}

August 21, 2014

\begin{abstract}
In this paper, we propose an extension of the productivity decomposition method developed by Olley \& Pakes (1996). This extension provides an accounting for the contributions of both firm entry and exit to aggregate productivity changes. It breaks down the contribution of surviving firms into a component accounting for changes in the firm-level distribution of productivity and another accounting for market share reallocations among those firms - following the same methodology as the one proposed by Olley \& Pakes (1996). We argue that the other decompositions that break-down aggregate productivity changes into these same four components introduce some biases in the measurement of the contributions of entry and exit.

We apply our proposed decomposition to the large measured increases of productivity in Slovenian manufacturing during the 1995-2000 period and contrast our results with those of other decompositions. We find that, over a 5 -year period, the measurement bias associated with entry and exit is substantial, accounting for up to 10 percentage points of aggregate productivity growth. We also find that market share reallocations among surviving firms played a much more important role in driving aggregate productivity changes.
\end{abstract}

Keywords: Productivity Decomposition, Industry Productivity

JEL Classification Numbers: C10, O47

\section{Introduction}

Aggregate productivity is a weighted average of productivity at the producer level (firm or plant). Empirically, these producers have vastly different productivity levels, even when the aggregation occurs over narrowly defined sectors. Aggregate productivity changes over time then need not only reflect shifts in the distribution of producer-level productivity. Holding this distribution fixed, aggregate productivity can also change due to composition changes between firms: Due to changes

\footnotetext{
${ }^{*}$ This article was produced in the framework of MICRO-DYN (www.micro-dyn.eu ), an international economic research project focusing on the competitiveness of firms, regions and industries in the knowledge-based economy. The project is funded by the EU Sixth Framework Programme (www.cordis.lu). This publication reflects only the author's views, the European Community is not liable for any use that may be made of the information contained therein.

${ }^{\dagger}$ Department of Economics. Harvard University. Littauer Center 215. Cambridge, MA 02138.

${ }^{\ddagger}$ Faculty of Economics, University of Ljubljana, Kardeljeva pl. 17, 1000 Ljubljana. E-mail: saso.polanec@ef.unilj.si.
} 
in market shares among surviving firms, but also due to the entry of new producers and the exit of old ones. Empirical studies spanning many different countries, industries, and time horizons have consistently shown that those composition changes are an important driver of aggregate productivity changes (See Foster, Haltiwanger and Krizan, 2001; and Bartelsman, Haltiwanger and Scarpetta, 2013). This finding has spurred the development of productivity decomposition methods that can break-down aggregate productivity changes into those 4 different components (productivity distribution shifts among survivors, market share reallocations among survivors, entry, and exit). Several of these decomposition methods are based on following individual producers from one period to the next, tracking changes in both their market shares and their productivity (An entrant is interpreted as a firm whose market share increases from zero; Similarly, an exiter is interpreted as a firm whose market share decreases to zero.). One notable exception is a decomposition based on moments of the joint distribution of market shares and productivity developed by Olley and Pakes (1996) - hereafter OP. That method does not accommodate entry and exit, in the sense that it does not decompose aggregate productivity changes into components that are driven by entry and exit. For a given set of firms, the weighted average of productivity is decomposed into a moment of the firm productivity distribution (the unweighted mean), and a moment of the joint distribution with market shares (the covariance between productivity and market shares).

In this paper, we extend the OP decomposition to also measure the contributions of entry and exit. We argue that this extension eliminates biases in the measurement of those entry/exit contributions that are a feature of the other decomposition methods that follow individual producers over time. Empirically, we show that these biases are substantial for the case of Slovenia's transition period from 1995 to 2000, especially when considering longer time spans. Our empirical results also show that the contribution of market share reallocations among surviving firms to productivity growth is much more substantial, once the biases regarding entry and exit measurement are eliminated.

Setting aside the measurement of entry and exit, the OP decomposition has an attractive feature relative to the decompositions that track individual firms over time: Because it is based on moments of the distributions of productivity and market shares, it can be more directly connected to theoretical models with firm productivity heterogeneity that have been developed to analyze the pattern of market share reallocations across firms and its consequences for aggregate productivity. ${ }^{1}$

\footnotetext{
${ }^{1}$ See, for example, Bartelsman et al. (2013), Hsieh and Klenow (2009), and Collard-Wexler, Asker and De Loecker (2011).
} 
Given a distribution of firm productivity, these models feature a market mechanism that determines an allocation of market shares to those firms based on their productivity and other firm and market characteristics. This implies a given covariance between those market shares and firm productivity - which is one of the key moments tracked by the OP decomposition. The other moment, the unweighted productivity mean, tracks shifts in the distribution of productivity. (Of course, higher moments of both the productivity distribution and its joint distribution with market shares may also be important for the theoretical models, but nailing down the first moments is a necessary first step.) Historically, the analysis of aggregate productivity changes across countries and over time has focused on the distribution of firm productivity (centered at its unweighted mean). However, much of the recent literature has shown that differences in the market-share covariance account for substantial portions of those aggregate productivity changes (both over time and across countries).

Since our goal is to highlight differences in decomposition methods, we have picked an empirical case of an economy in transition that exhibits very large productivity changes: depending on the measure of productivity used (labor or TFP), aggregate manufacturing productivity in Slovenia increased between 40\% and 50\% from 1995 to 2000 (See Polanec, 2004). There is thus a substantial productivity change to be decomposed into the 4 components we have discussed (productivity distribution shifts among survivors, market share reallocations among survivors, entry, and exit). We contrast the results from our decomposition method with the two main methods that are currently used to break-down productivity changes into those same 4 components: One by Griliches \& Regev (1995) - hereafter GR - and the other by Foster et al. (2001) - hereafter FHK. Both methods are refinements of a decomposition developed by Baily, Hulten and Campbell (1992) hereafter BHC, who were the first to report a break down of aggregate productivity change into those 4 components for U.S. manufacturing. These decomposition methods all produce different measures for the same four components of aggregate productivity. This has induced some discussion detailing the sources of those differences. In this paper, we argue that all those decompositions suffer from some biases that stem from their construction method. In general, the theoretical direction of those biases (as well as their magnitudes) is ambiguous. For the case of a fast growing economy (such as Slovenia from 1995 to 2000), we show theoretically that this bias involves an overmeasurement of the contribution of entry. Our empirical decompositions show that the magnitude of this bias is substantial and is then also reflected in a substantial under-measurement of the contribution of surviving firms to aggregate productivity growth. In particular, the component reflecting market share reallocations among surviving firms is most severely under-measured: we 
find that its contribution to productivity growth is 2-3 times larger than in the GR and FHK decompositions.

The remainder of the paper is organized as follows: In the next section, we review the existing decompositions for aggregate productivity. In the following section, we define our new decomposition and discuss the key measurement differences with the other decompositions. In the fourth section, we empirically decompose Slovenia's substantial productivity growth, contrasting the results obtained from our decomposition with the ones from the GR and FHK decompositions. The fifth and last section concludes.

\section{Review of Existing Decompositions}

All methods start with a definition of aggregate productivity at time $t$ as a share-weighted average of firm productivity $\varphi_{i t}$ :

$$
\Phi_{t}=\sum_{i} s_{i t} \varphi_{i t}
$$

where the shares $s_{i t} \geq 0$ sum to 1 . The key variable of interest is the change in aggregate productivity over time (from $t=1$ to 2 ) $\Delta \Phi=\Phi_{2}-\Phi_{1}$. There are many potential choices for the data counterparts representing the share weight $s_{i t}$ and productivity measure $\varphi_{i t}$. We review those choices below with our empirical application. For now, we note that our decomposition does not depend on any particular choice of weight or productivity measure. Our starting point is that those choices are such that $\Delta \Phi$ captures a meaningful dimension of aggregate productivity change (which we seek to decompose). Since this productivity change is measured in differences, we assume that the underlying productivity measure $\varphi_{i t}$ is in $\operatorname{logs}-$ so $\Delta \Phi$ represents a percentage change. In the appendix, we develop an alternate version of our decomposition that applies to productivity measures in levels. ${ }^{2}$

In their seminal contribution, Baily et al. (1992) follow firms over time, tracking their changes to both shares $s_{i t}$ and productivity $\varphi_{i t}$. The contribution of each firm to the aggregate productivity change $\Delta \Phi, s_{i 2} \varphi_{i 2}-s_{i 1} \varphi_{i 1}$, is then separated into three categories for surviving, entering, and exiting firms - where $s_{i 1}=0$ for entrants and $s_{i 2}=0$ for exiters (and the unoberserved productivity $\varphi_{i t}$ when $s_{i t}=0$ is irrelevant). The change in weighted productivity for the surviving firms can then be

\footnotetext{
${ }^{2}$ The existing literature on productivity decompositions typically uses a productivity measure in logs. The advantage of the firm-level measure in levels is that the aggregate productivity measure can have a direct data counterpart. For example, if productivity is measured as valued-added per worker and the weights are employment shares, then $\Phi_{t}$ measures aggregate value added per worker.
} 
decomposed into a sum of the productivity changes holding the firms' shares constant (within-firm component) and a sum of the share changes holding the firms' productivity constant (between-firm component). The resulting decomposition of the aggregate productivity change is:

$$
\begin{aligned}
\Delta \Phi & =\sum_{i \in S}\left(s_{i 2} \varphi_{i 2}-s_{i 1} \varphi_{i 1}\right)+\sum_{i \in E} s_{i 2} \varphi_{i 2}-\sum_{i \in X} s_{i 1} \varphi_{i 1} \\
& =\sum_{i \in S} s_{i 1}\left(\varphi_{i 2}-\varphi_{i 1}\right)+\sum_{i \in S}\left(s_{i 2}-s_{i 1}\right) \varphi_{i 2}+\sum_{i \in E} s_{i 2} \varphi_{i 2}-\sum_{i \in X} s_{i 1} \varphi_{i 1}
\end{aligned}
$$

where $S, E$ and $X$ denote the sets of surviving, entering and exiting firms, respectively. The first line breaks down the productivity change across those three groups, and the second line further breaks down the contribution for surviving firms into two sub-components. The first term is the within-firm sub-component. It aims to capture the contribution of productivity improvements within surviving firms. The second term is the between-firm sub-component that seeks to capture the contribution of market share changes between surviving firms.

The GR and FHK decompositions use the same approach as the BHC decomposition, following firms over time and tracking both share and productivity changes. The main difference with $\mathrm{BHC}$ is that both methods introduce a reference average productivity level. Since the shares $s_{i t}$ sum to one in both periods, the contribution of each firm to the productivity change $\Delta \Phi$ can be written as a difference with respect to any chosen reference productivity level $\Phi_{R E F}: \Delta \Phi=$ $\sum_{i}\left[s_{i 2}\left(\varphi_{i 2}-\Phi_{R E F}\right)-s_{i 1}\left(\varphi_{i 1}-\Phi_{R E F}\right)\right]$. This reference productivity level $\Phi_{R E F}$ is then used as a benchmark to evaluate the contributions of entrants and exiters relative to surviving firms.

Griliches and Regev (1995) use the average aggregate productivity level between the two periods, $\bar{\Phi}=\left(\Phi_{1}+\Phi_{2}\right) / 2$, as the reference productivity level. Their decomposition is then given by:

$$
\begin{aligned}
\Delta \Phi & =\sum_{i \in S}\left[s_{i 2}\left(\varphi_{i 2}-\bar{\Phi}\right)-s_{i 1}\left(\varphi_{i 1}-\bar{\Phi}\right)\right]+\sum_{i \in E} s_{i 2}\left(\varphi_{i 2}-\bar{\Phi}\right)-\sum_{i \in X} s_{i 1}\left(\varphi_{i 1}-\bar{\Phi}\right) \\
& =\sum_{i \in S} \bar{s}_{i}\left(\varphi_{i 2}-\varphi_{i 1}\right)+\sum_{i \in S}\left(s_{i 2}-s_{i 1}\right)\left(\bar{\varphi}_{i}-\bar{\Phi}\right)+\sum_{i \in E} s_{i 2}\left(\varphi_{i 2}-\bar{\Phi}\right)-\sum_{i \in X} s_{i 1}\left(\varphi_{i 1}-\bar{\Phi}\right) .
\end{aligned}
$$

In the second line, the contribution of surviving firms is broken into within- and between-firm subcomponents using an average (between periods) firm share $\bar{s}_{i}=\left(s_{i 1}+s_{i 2}\right) / 2$ and an average firm productivity $\bar{\varphi}_{i}=\left(\varphi_{i 1}+\varphi_{i 2}\right) / 2$ constructed in the same way as the average aggregate productivity $\bar{\Phi}$. The first line of the decomposition clearly shows how the introduction of the reference productivity 
level $\bar{\Phi}$ impacts the measured contributions of entry and exit relative to surviving firms. In the BHC decomposition (where $\Phi_{R E F}=0$ ), the contribution of entry is always positive - regardless of the productivity of entrants - and the contribution of exit is always negative - again regardless of the productivity of exiters. The GR decomposition more accurately reflects the fact that the contribution of entrants and exiters to aggregate productivity changes can be positive or negative, depending on whether the productivity levels for that subset of firms are above or below the reference productivity level. However, in the next section we will argue that the GR decomposition still introduces some bias into the measurement of the contributions of entry and exit (and hence also to the contribution of surviving firms) to aggregate productivity changes.

Foster et al. (2001) use the aggregate productivity level in period $1 \Phi_{1}$ instead of the time average $\bar{\Phi}$ as a reference productivity level. Their decomposition is then given by:

$$
\begin{array}{r}
\Delta \Phi=\sum_{i \in S}\left[s_{i 2}\left(\varphi_{i 2}-\Phi_{1}\right)-s_{i 1}\left(\varphi_{i 1}-\Phi_{1}\right)\right]+\sum_{i \in E} s_{i 2}\left(\varphi_{i 2}-\Phi_{1}\right)-\sum_{i \in X} s_{i 1}\left(\varphi_{i 1}-\Phi_{1}\right) \\
=\sum_{i \in S} s_{i 1}\left(\varphi_{i 2}-\varphi_{i 1}\right)+\sum_{i \in S}\left(s_{i 2}-s_{i 1}\right)\left(\varphi_{i 1}-\Phi_{1}\right)+\sum_{i \in S}\left(s_{i 2}-s_{i 1}\right)\left(\varphi_{i 2}-\varphi_{i 1}\right) \\
+\sum_{i \in E} s_{i 2}\left(\varphi_{i 2}-\Phi_{1}\right)-\sum_{i \in X} s_{i 1}\left(\varphi_{i 1}-\Phi_{1}\right) .
\end{array}
$$

As with the 2 preceding decompositions, the first line separates out the contributions of surviving, entering, and exiting firms to the productivity change. The second line then also splits the contribution of surviving firms into within- and between-firm sub-components (the first two terms), but also incorporates a new third sub-component (labeled as a "cross" firm component) that captures the covariance between changes in market share and changes in productivity. As with the GR decomposition, the contributions of entry and exit can be either positive or negative, although their sign now depends on the productivity of entrants and exiters relative to a different productivity benchmark (the aggregate productivity in period $1 \Phi_{1}$ ). This also attenuates the bias previously mentioned with respect to the $\mathrm{BHC}$ decomposition, but we again will argue that some bias still remains.

The other commonly used decomposition proposed by Olley \& Pakes (1996) eschews following firms over time and instead is based on a decomposition of the aggregate productivity level $\Phi_{t}$ in 
each period. This decomposition is:

$$
\begin{aligned}
\Phi_{t} & =\bar{\varphi}_{t}+\sum_{i}\left(s_{i t}-\bar{s}_{t}\right)\left(\varphi_{i t}-\bar{\varphi}_{t}\right) \\
& =\bar{\varphi}_{t}+\operatorname{cov}\left(s_{i t}, \varphi_{i t}\right)
\end{aligned}
$$

where $\bar{\varphi}_{t}=\frac{1}{n_{t}} \sum_{i=1}^{n_{t}} \varphi_{i t}$ is the unweighted firm productivity mean and $\bar{s}_{t}=1 / n_{t}$ is the mean market share. We have introduced a slight abuse of notation with the definition of the cov operator, which would typically be multiplied by $1 / n_{t}$. However, since $s_{i t} \mathrm{~s}$ are market shares, they essentially already incorporate the division by the number of firms $n_{t}$. Changes in productivity over time $\Delta \Phi$ are then simply given by the change in the unweighted mean $\Delta \bar{\varphi}$ and the change in covariance $\Delta$ cov. This provides a natural way of decomposing productivity changes into a component capturing shifts in the productivity distribution (via the change in the first moment $\Delta \bar{\varphi}$ ) and another component capturing market share reallocations via the change in covariance. This term is different than the cross term from the FHK decomposition, which captures the covariance of market share and productivity changes for an individual firm. On the other hand, the OP covariance is measured purely in the joint cross-sectional distribution of market shares and productivity: it increases with the correlation between market shares and productivity. In the next section, we extend this decomposition to accommodate entry and exit, and argue that it more accurately captures the separate contributions to aggregate productivity changes of entrants, exiters, and surviving firms. Within these 3 groups of firms, our decomposition preserves the attractive features of the original OP decomposition in providing a natural additional decomposition between shifts in the distribution of productivity and market share reallocations.

\section{Dynamic Olley-Pakes Decomposition with Entry and Exit (DOPD)}

Let $s_{G t}=\Sigma_{i \in G} s_{i t}$ represent the aggregate market share of a group $G$ of firms and define $\Phi_{G t}=$ $\Sigma_{i \in G}\left(s_{i t} / s_{G t}\right) \varphi_{i t}$ as that group's aggregate (average) productivity. We can then write aggregate productivity in each period as a function of the aggregate share and aggregate productivity of the three groups of firms (survivors, entrants, and exiters):

$$
\begin{aligned}
& \Phi_{1}=s_{S 1} \Phi_{S 1}+s_{X 1} \Phi_{X 1}=\Phi_{S 1}+s_{X 1}\left(\Phi_{X 1}-\Phi_{S 1}\right) \\
& \Phi_{2}=s_{S 2} \Phi_{S 2}+s_{E 2} \Phi_{E 2}=\Phi_{S 2}+s_{E 2}\left(\Phi_{E 2}-\Phi_{S 2}\right) .
\end{aligned}
$$


From this, we obtain the productivity change $\Delta \Phi$ in terms of those components and then separately apply the OP decomposition (5) to the contribution of the surviving firms:

$$
\begin{aligned}
\Delta \Phi & =\left(\Phi_{S 2}-\Phi_{S 1}\right)+s_{E 2}\left(\Phi_{E 2}-\Phi_{S 2}\right)+s_{X 1}\left(\Phi_{S 1}-\Phi_{X 1}\right) \\
& =\Delta \bar{\varphi}_{S}+\Delta \operatorname{cov}_{S}+s_{E 2}\left(\Phi_{E 2}-\Phi_{S 2}\right)+s_{X 1}\left(\Phi_{S 1}-\Phi_{X 1}\right) .
\end{aligned}
$$

The first line decomposes the aggregate productivity change into components for the three groups of firms: survivors, entrants, and exiters. In the second line, we apply the OP decomposition (5) to the contribution of surviving firms - further separating that component into one induced by a shift in the distribution of firm productivity (the unweighted mean change in the productivity of surviving firms $\Delta \bar{\varphi}_{S}$ ), and another one induced by market share reallocations (the covariance change between market share and productivity for surviving firms $\left.\Delta \operatorname{cov}_{S}\right){ }^{3}$ We can also further decompose the contributions of entrants and exiters in a similar way. ${ }^{4}$

As our decomposition leverages the cross-sectional OP decomposition, the first step of separating out the contributions by survivors, entrants, and exiters need not use the same reference productivity level for all three groups. This is a necessary feature of the other decompositions that track individual firms over time. Table 1 highlights those differences between our decomposition and the GR and FHK decompositions. It contrasts the contributions of surviving, entering, and exiting firms across the three decompositions. The first two columns clearly show how the same reference productivity level must be used to evaluate the contributions of the three groups of firms for the GR and FHK decompositions. In our proposed decomposition (third column), we can use different reference productivity levels for all three groups.

All three decompositions feature a contribution of entry that increases with the aggregate productivity of entrants $\Phi_{E 2}$, a contribution of exit that increases with lower aggregate productivity of exiters $\Phi_{X 1}$, and a contribution of surviving firms that increases with the aggregate productivity difference $\Phi_{S 2}-\Phi_{S 1}$. (Needless to say, all three also add up to the same aggregate productivity change $\Delta \Phi$.) However, we argue that our decomposition more accurately reflects the contributions of those three groups in the sense that we can relate each group contribution to a specific couter-

\footnotetext{
${ }^{3}$ The relevant market shares for this covariance term is the firm's market share within the subset of surviving firms (so those market share sum to 1 within this subgroup).

${ }^{4}$ The contribution of entry can be decomposed into one component reflecting differences in the productivity distribution between entrants and surviving firms, $s_{E 2}\left(\bar{\varphi}_{E 2}-\bar{\varphi}_{S 2}\right)$, and another component reflecting differences in the covariance between market shares and productivity for the two groups, $s_{E 2}\left(\operatorname{cov}_{E 2}-\operatorname{cov}_{S 2}\right)$. The decomposition for exit is very similar. We do not show those further decompositions above in order to maintain the parallel with the 4 components of the GR and FHK decompositions.
} 
Table 1: Productivity Contributions of Surviving, Entering, and Exiting Firms

\begin{tabular}{cccc}
\hline \hline Group & GR & FHK & DOPD \\
\hline Surviving & $s_{S 2}\left(\Phi_{S 2}-\bar{\Phi}\right)-s_{S 1}\left(\Phi_{S 1}-\bar{\Phi}\right)$ & $s_{S 2}\left(\Phi_{S 2}-\Phi_{1}\right)-s_{S 1}\left(\Phi_{S 1}-\Phi_{1}\right)$ & $\Phi_{S 2}-\Phi_{S 1}$ \\
Firms & $s_{E 2}\left(\Phi_{E 2}-\bar{\Phi}\right)$ & $s_{E 2}\left(\Phi_{E 2}-\Phi_{1}\right)$ & $s_{E 2}\left(\Phi_{E 2}-\Phi_{S 2}\right)$ \\
Entering & $s_{X 1}\left(\bar{\Phi}-\Phi_{X 1}\right)$ & $s_{X 1}\left(\Phi_{1}-\Phi_{X 1}\right)$ & $s_{X 1}\left(\Phi_{S 1}-\Phi_{X 1}\right)$ \\
Firms & & & \\
Exiting & & & \\
Firms & &
\end{tabular}

factual scenario as follows: The contribution of surviving firms is simply the aggregate productivity that would have been observed absent entry and exit. Since neither the productivity of entrants in period 1, nor the productivity of exiters in period 2, are observed, we cannot use an identical counterfactual for those two groups of firms. Instead, we can use the set of surviving firms as a benchmark and ask how adding the group of entrants (or exiters) affects the aggregate productivity change. Thus, our contribution of entry, $s_{E 2}\left(\Phi_{E 2}-\Phi_{S 2}\right)$, is the change in aggregate productivity $\Delta \Phi$ generated by adding/removing the group of entrants. Similarly, our contribution of exit, $s_{X 1}\left(\Phi_{S 1}-\Phi_{X 1}\right)$, is the change in aggregate productivity $\Delta \Phi$ generated by adding/removing the group of exiting firms.

We note that using a different reference productivity level for entrants and exiters is critical in order to apply this 'counterfactual' definition. Entrants generate positive productivity growth if (and only if) they have higher productivity $\Phi_{E 2}$ than the remaining (surviving) firms $\Phi_{S 2}$ in the same time period when entry occurs $(t=2)$; Exiters generate positive productivity growth if (and only if) they have lower productivity $\Phi_{X 1}$ than the remaining (surviving) firms $\Phi_{S 1}$ in the same time period when exit occurs $(t=1)$. Because the GR and FHK decompositions follow surviving firms over time, they need to use the same reference productivity levels for entrants and exiters. Any choice of reference productivity level will necessarily lead to a bias in measuring the contribution of one group or the other (and potentially to a bias for both groups). When there is productivity growth, the reference level for surviving firms reflects that growth and $\Phi_{S 2}>\Phi_{S 1}$. The reference productivity levels $\Phi_{1}$ (for FHK) and $\bar{\Phi}$ (for GR) are then below $\Phi_{S 2}$, leading to an over-measurement of the contribution of entry for both decompositions (and hence an undermeasurement of the contribution for the remaining two groups of firms).

Consider the following hypothetical example of an economy with productivity growth rate $\gamma>0$ among representative firms (same productivity level across firms that is growing at rate $\gamma$ ). Now add 
entry and exit of a portion of those representative firms. The economy's rate of productivity growth is still $\gamma$, which is the same growth rate as in the absence of entry and exit. Our decomposition therefore assigns a zero net contribution to the $\gamma$ rate of productivity growth for entry and exit. On the other hand, the GR decomposition assigns a net contribution of $s_{E} \gamma / 2$ for entry and $s_{X} \gamma / 2$ for exit; The FHK decomposition assigns a net contribution of $s_{E} \gamma$ for entry and zero for exit. In both cases, a positive net contribution is assigned to entry when this entry does not affect the economy's rate of productivity growth. In the following section, we apply all three decompositions to the fast growing Slovenian economy, and show that this over-measurement is quite substantial.

For any given contribution of surviving firms to the aggregate productivity growth, our empirical application also exhibits substantial differences in the decomposition of this growth into withinand between-firm components. For the 1995-2000 cumulative period, we find a substantially larger contribution of the between-firm component (relative to GR and FHK). These discrepancies relative to the existing OP, GR, and FHK decompositions that have also been highlighted in other work. (A priori, there is no clear way of signing the direction of those discrepancies.) As we argued in the introduction, the OP decomposition has the attractive property of a direct connection with theoretical models of firm productivity dynamics. The contribution of our current work is to adapt this decomposition to incorporate entry and exit.

\section{Empirical Application: Slovenian Manufacturing 1995-2000}

We use accounting firm-level panel data covering the entire Slovenian manufacturing sector (NACE 2-digit industries 15-37) for the 1995-2000 period. ${ }^{5}$ During this time, the manufacturing sector (and the rest of the economy) went through significant structural changes that were triggered by economic reforms adopted in the late 1980s and early 1990s (e.g. liberalization of prices and wages, deregulation of firm entry, and privatization of state-owned firms). The shock caused by economic reforms initially led to large declines in both aggregate output and labor productivity, followed by a fast reversal to high growth, which was sustained through our entire sample period. During that time, value added per worker increased nearly 50\%. Previous empirical research using Slovenian manufacturing data (Polanec, 2004; Bartelsman, Haltiwanger and Scarpetta, 2009) has established that an important part of this aggregate productivity growth was driven by market share reallocation between surviving, entering and exiting firms. This evidence that all four channels

\footnotetext{
${ }^{5}$ We are grateful to the Slovenian Agency for Public Legal Records and Related Services (AJPES) for providing the data.
} 
contributed to substantial aggregate productivity gains makes our data set ideal for illustrating our new decomposition, and contrasting its predictions with the GR and FHK decompositions.

\section{Description of Data}

The data set contains information on firm identity, year of reporting, annual sales, costs of materials and services, nominal physical capital and employment. From these we can calculate (or estimate) all the standard measures for labor and total factor productivity at the firm level. We deflate firm revenue and material costs by the firm's NACE 2-digit producer price index, and physical capital by the price index for investment goods. The reported number of employees is calculated from the annual number of hours worked by all workers.

Table 2 reports summary statistics for the first and last year of our sample (1995 and 2000). In order to include the same set of firms in all decompositions (regardless of the productivity and share measure used), we only keep firms that employ at least one worker, have positive physical capital, and generate positive value added. The remaining number of firms in our sample increases by $18.4 \%$ between 1995 and 2000, from 3,867 to 4,580. Among these firms were 2,677 survivors, 1,903 entrants and 1,191 exiters (based on transitions from 1995 to 2000; we break down transitions at intermediate time intervals later on). Over this time, the average size of active firms, measured by employment, decreased from 60.1 to 45.2 employees, mainly driven by the entry of smaller new firms (size reductions by surviving firms played a more minor role). ${ }^{6}$ The downsizing of surviving firms and the exit of firms also contributed to a decline in aggregate employment by $11.2 \%$, from 233 to 207 thousand workers. Nevertheless, real aggregate sales, real aggregate value added and real aggregate physical capital all substantially increased over that time span: by $46.1 \%, 45.8 \%$ and $25.3 \%$, respectively.

\section{Choice of Productivity Measure and Weights}

There are numerous possibilities for the choice of a productivity measure and associated market share weight. Foster et al. (2001) discuss how these choices can affect the decomposition of aggregate productivity for a given decomposition method. Our goal is to contrast the different decomposition methods for a given choice of productivity measure and weights. We restrict our analysis to two main productivity measures and associated weights: one measure of labor pro-

\footnotetext{
${ }^{6}$ The average employment of surviving firms between 1995 and 2000 declined from 67.4 to 59.4 employees. In 2000 , the average employment of entrants was 25.1 employees.
} 
Table 2: Descriptive Statistics for Slovenian Manufacturing Firms in 1995 and 2000

\begin{tabular}{lcc}
\hline \hline & \multicolumn{2}{c}{ Year } \\
\cline { 2 - 3 } Number of & 1995 & 2000 \\
\hline All firms & 3867 & 4580 \\
Surviving firms & 2677 & 2677 \\
Entering firms & - & 1903 \\
Exiting firms & 1191 & - \\
& \multicolumn{2}{c}{ Year } \\
\cline { 2 - 3 } & 1995 & 2000 \\
Variable & 60.1 & 45.2 \\
Average employment & 232 & 206 \\
Aggregate employment [in thousand] & 425 & 620 \\
Real aggregate value added [in bln. SIT] & 1520 & 2220 \\
Real aggregate output [in bln. SIT] & 862 & 1080 \\
Real aggregate physical capital [in bln. SIT] & \multicolumn{2}{c}{} \\
\hline Notes: The nominal value added and output are deflated by 2-digit \\
NACE industry-level producer price indices. The nominal physical cap- \\
ital is deflated by investment goods price index. \\
Source: AJPES and own calculations.
\end{tabular}

ductivity with employment shares as weights, and one measure of total factor productivity (TFP) with nominal-value-added shares as weights. We directly compute labor productivity as the log of value-added per worker. We estimate TFP for our second measure as the residual of the firm-level production function regression separately for all NACE 2-digit industries:

$$
\ln T F P_{i t}=\ln Y_{i t}-\hat{\alpha} \ln K_{i t}-\hat{\beta} \ln L_{i t}
$$

where $Y_{i t}, K_{i t}$ and $L_{i t}$ denote the real value added, real capital and employment of firm $i$ in period $t$, and $\hat{\alpha}$ and $\hat{\beta}$ denote the regression coefficients for capital and labor. We use a value-added production function (and nominal-value-added weights) instead of one based on gross output (with intermediate inputs in the production function), as Petrin and Levinsohn (2012) argue that the former yields productivity estimates that have a much more direct welfare interpretation. However, we have also experimented with TFP based on gross output production function regressions and corresponding weights equal to gross output shares, and the qualitative features that we emphasize are robust to this alternative productivity measure. ${ }^{7}$

There is a vast (and growing) literature on productivity estimation that explores many asso-

\footnotetext{
${ }^{7}$ The results are also robust to estimates of production function using the control-function approach proposed by Olley and Pakes (1996).
} 
ciated measurement and estimation issues. One of those issues is the simultaneity bias between shocks to productivity and changes in variable inputs (typically labor in a value-added production function framework). For our sample, correcting for this bias does not substantially change the labor and capital elasticities, and hence has negligible effects on the productivity rankings and year to year changes that are the key ingredients for our productivity decompositions (along with the shares, which are directly measured). Another important issue is the unobserved firm price, which affects the measures of output (gross or value-added). Foster et al. (2008) find that entering firms charge lower prices relative to incumbent firms. This depresses the measurement of the physical output of entrants relative to incumbents. Thus, we should be clear that our productivity measure relates to revenues and not physical output.

More generally, we emphasize again that our focus is on the contrast between decomposition methods for a given set of productivity measures and weights. Addressing the numerous measurement issues for firm productivity will lead to a different starting point for the decompositions; but the contrast between the decompositions that we highlight will remain. Those differences are based on the use of a sample featuring strong productivity growth among incumbent firms. In addition, one of our productivity measures, value added per worker, is directly computed, and thus of direct interest. In the appendix, where we adapt our decomposition to productivity changes in levels (not in logs), the aggregate productivity measure is simply aggregate manufacturing value added per worker. This variable is clearly relevant and important, regardless of the productivity measurement issues discussed above.

\section{Results}

We report the results from the GR and FHK decompositions, and our proposed dynamic OP decomposition with entry and exit (DOPD) in table 3. In order to focus on the differences associated with the contribution of entry, we initially report a single productivity contribution for the surviving firms - along with the contribution of entering and exiting firms (following the first line of the decompositions $3,4,6)$. We then separately report the within- and between-firm components for surviving firms in the next table. The top panel is based on the labor productivity measure with employment shares, and the bottom panel is based on the TFP measure with nominal-valueadded weights. We report decompositions between 1995 and all subsequent years until 2000 in order to illustrate how the measurement biases are affected by the length of the time span. For each decomposition, the contributions of surviving, entering, and exiting firms sum to the same 
aggregate productivity change listed in the far-right column. All productivity changes are reported as log percents (or log points) - and can thus be interpreted as percentage point changes.

Table 3: Comparison of Decompositions

Aggregate Productivity Change Relative to 1995

\begin{tabular}{|c|c|c|c|c|c|c|c|c|c|c|}
\hline \multirow[b]{2}{*}{ Year } & \multicolumn{3}{|c|}{ Surviving Firms } & \multicolumn{3}{|c|}{ Entering Firms } & \multicolumn{3}{|c|}{ Exiting Firms } & \multirow{2}{*}{$\begin{array}{c}\text { All } \\
\text { Firms }\end{array}$} \\
\hline & GR & FHK & DOPD & GR & FHK & DOPD & GR & FHK & DOPD & \\
\hline \multicolumn{11}{|c|}{ Labor Productivity (in log percent) - Emp. Share Weights } \\
\hline 1996 & 12.14 & $12 . \overline{30}$ & 12.77 & -2.49 & -2.21 & -2.90 & 3.55 & 3.11 & 3.33 & 13.20 \\
\hline 1997 & 24.89 & 25.21 & 28.51 & -0.44 & 1.41 & -2.61 & 6.63 & 4.46 & 5.18 & 31.08 \\
\hline 1998 & 25.12 & 25.59 & 29.91 & 0.70 & 3.33 & -2.28 & 9.06 & 5.95 & 7.24 & 34.88 \\
\hline 1999 & 31.48 & 31.30 & 39.10 & 1.73 & 5.99 & -3.15 & 9.83 & 5.75 & 7.10 & 43.05 \\
\hline 2000 & 34.65 & 34.47 & 44.90 & 4.08 & 9.90 & -2.25 & 11.60 & 5.96 & 7.68 & 50.33 \\
\hline \multicolumn{11}{|c|}{ TFP (in log percent) - Value-added Share Weights } \\
\hline 1996 & 11.13 & 11.22 & 11.56 & 0.31 & 0.48 & 0.15 & 0.23 & -0.04 & -0.04 & 11.67 \\
\hline 1997 & 19.83 & 19.84 & 22.07 & 2.70 & 3.89 & 1.68 & 1.02 & -0.20 & -0.21 & 23.55 \\
\hline 1998 & 20.10 & 20.10 & 23.08 & 1.98 & 3.54 & 0.48 & 2.09 & 0.53 & 0.61 & 24.17 \\
\hline 1999 & 22.04 & 26.60 & 32.30 & 4.35 & 7.34 & 1.65 & 2.35 & -0.09 & -0.10 & 33.85 \\
\hline 2000 & 24.42 & 28.02 & 35.58 & 6.11 & 10.13 & 2.64 & 2.97 & -0.35 & -0.41 & 37.82 \\
\hline
\end{tabular}

Source: AJPES and own calculations.

As we compare the contributions of entry across the three tables, we can easily verify the direction of the over-measurement that we previously motivated for the GR and FHK decompositions (relative to our decomposition). All three decompositions roughly measure the same contribution for entry over the 1 year interval from 1995 to 1996: negative 2-3 percentage points for labor productivity and 0 for TFP. However, as the time span increases, we see that the contributions of entry for the GR and FHK decompositions steadily increase, up to 9-10 percentage points for FHK and up to 4-5 percentage points for GR. On the other hand, our decomposition reports that this contribution of entry remains steady at all the different time spans: slightly negative for labor productivity and slightly positive for TFP.

Consider first the case of labor productivity. Table 4 reports the underlying aggregate labor productivity and share data for all three groups of firms across all time spans. Our decomposition reports a negative contribution of entry to aggregate labor productivity change because, in any given year, entrants have an aggregate productivity $\Phi_{E 2}$ that is below the aggregate productivity of surviving firms $\Phi_{S 2}$ for that time period (see bottom panel of Table 4). Thus, in all sample years, the entrants' productivity is below the overall aggregate productivity level $\Phi_{2}$ : their presence 
pulls the aggregate productivity level downward. Concurrently, the aggregate productivity of both surviving firms and entrants is steadily growing, year over year. Part of this growth is attributed to the contribution of entry to aggregate productivity growth in the GR and FHK decompositions. (This is why those decompositions report a contribution of entry that is growing with the timespan.) We describe this finding of a large positive contribution of entry for those decompositions as a bias, because it does not reflect the fact that entrants are pushing the aggregate productivity level downward (in any given year). Table 3 shows that this bias can be empirically substantial, accounting for 6-12 percentage points of aggregate productivity growth over 5 years.

Table 4: Aggregate Labor Productivity and Employment Shares

\begin{tabular}{|c|c|c|c|c|c|c|}
\hline & & \multicolumn{5}{|c|}{$\overline{I n} t=1$} \\
\hline \multicolumn{2}{|c|}{ Year } & \multicolumn{2}{|c|}{ Surviving Firms } & \multicolumn{2}{|c|}{ Exiting Firms } & \multirow{2}{*}{$\begin{array}{c}\text { All Firms } \\
\Phi_{1} \\
\end{array}$} \\
\hline$t=1$ & $t=2$ & $\Phi_{S 1}$ & $s_{S 1}$ & $\Phi_{X 1}$ & $s_{X 1}$ & \\
\hline 1995 & 1996 & 7.4634 & 0.9334 & 6.9471 & 0.0666 & 7.4289 \\
\hline 1995 & 1997 & 7.4821 & 0.8606 & 7.1013 & 0.1394 & 7.4289 \\
\hline 1995 & 1998 & 7.5037 & 0.8217 & 7.0847 & 0.1783 & 7.4289 \\
\hline 1995 & 1999 & 7.5037 & 0.8106 & 7.1093 & 0.1894 & 7.4289 \\
\hline \multirow[t]{2}{*}{1995} & 2000 & 7.5109 & 0.7761 & 7.1450 & 0.2239 & 7.4289 \\
\hline & & \multicolumn{5}{|c|}{$\operatorname{In} t=2$} \\
\hline \multicolumn{2}{|c|}{ Year } & \multicolumn{2}{|c|}{ Surviving Firms } & \multicolumn{2}{|c|}{ Entering Firms } & All Firms \\
\hline$t=1$ & $t=2$ & $\Phi_{S 2}$ & $s_{S 2}$ & $\Phi_{E 2}$ & $s_{E 2}$ & $\Phi_{2}$ \\
\hline 1995 & 1996 & 7.6448 & 0.9570 & 6.9752 & 0.0430 & 7.6160 \\
\hline 1995 & 1997 & 7.8573 & 0.8805 & 7.6392 & 0.1195 & 7.8312 \\
\hline 1995 & 1998 & 7.9395 & 0.8492 & 7.7689 & 0.1508 & 7.9138 \\
\hline 1995 & 1999 & 8.0572 & 0.8022 & 7.8802 & 0.1978 & 8.0222 \\
\hline 1995 & 2000 & 8.1742 & 0.7690 & 8.0603 & 0.2310 & 8.1479 \\
\hline
\end{tabular}

Source: AJPES and own calculations.

Consider next the case of TFP. The same reasoning explains the over-measurement of the contribution of entry to aggregate TFP changes for the GR and FHK decompositions. The only difference is that entrants have roughly the same TFP levels (on average) as surviving firms. Thus, the contribution of entrants to productivity change is roughly nil, rather than slightly negative. (This is due to the fact that entrants use capital less intensively than surviving firms; this depresses their labor productivity relative to their TFP in comparison with surviving firms.) Nevertheless, the aggregate TFP of both entrants and surviving firms is growing year over year, leading to the same over-measurement issue that we previously described for labor productivity. 
In the case of a growing economy such as Slovenia, the over-measurement of the contribution of entry will be most severe for the FHK decomposition as it uses a lower reference productivity level $\Phi_{1}$ than the GR decomposition reference productivity level $\bar{\Phi}$. (In both cases, the over-measurement is induced by the fact that the reference productivity levels are below $\Phi_{S 2}$.) By the same token, this also means that the bias in the measurement of the contribution of exit for the FHK contribution will be less severe than for the GR decomposition. As we have argued in the previous section, the reference productivity level for the contribution of exit should be the aggregate productivity of surviving firms in that same time period, $\Phi_{S 1}$. The reference productivity level $\Phi_{1}$ for the FHK decomposition is closer to this reference point than the reference productivity level $\bar{\Phi}$, which is substantially greater than $\Phi_{S 1}$. Thus, the GR decomposition will substantially over-estimate the contribution of exit to productivity growth (as Table 3 also makes clear). As we previously noted, the use of a single reference productivity level for both entry and exit implies that the substantial productivity growth of surviving firms, $\Phi_{S 2}-\Phi_{S 1}$, will be attributed either to the contribution of entry or to that of exit.

For both the GR and FHK decompositions, this implies that the joint contribution of entry and exit will be substantially over-measured - leading to an equally-sized under-measurement of the contribution of surviving firms. Empirically, Table 3 reveals that the extent of this undermeasurement sums up to 7-10 percentage points of aggregate productivity growth over 5 years.

This under-measurement of the contribution of surviving firms is especially important for the quantitative relevance of the between-firm sub-component in explaining aggregate productivity changes. Table 5 breaks down the contribution for surviving firms into the within- and betweenfirm sub-components specified by the three decomposition methods (see the second line of the decompositions $3,4,6)$. These two sub-components are expressed as shares of the surviving firm productivity change from Table 3 in order to isolate differences associated with this subsequent decomposition. Thus, those shares sum to 100 percent for the GR and DOPD decompositions. In the case of FHK, the cross term is not reported; along with this missing term, the other two components sum to 100 percent. A priori, there is no clear direction for the differences between our within-between decomposition (which just mirrors the OP decomposition) and the other two decompositions. Empirically however, Table 5 shows that the share of the between component is substantially larger for OP-DOPD relative to the other two decomposition methods over our full 5 year sample. ${ }^{8}$ When we combine this under-measurement with the previously mentioned

\footnotetext{
${ }^{8}$ The between component is even negative for the FHK decomposition of TFP changes.
} 
Table 5: Contributions of Within-firm Growth and Between-firm Reallocations

\begin{tabular}{|c|c|c|c|c|c|c|}
\hline \multirow[b]{2}{*}{ Year } & \multicolumn{3}{|c|}{ Within } & \multicolumn{3}{|c|}{ Between } \\
\hline & GR & FHK & DOPD & GR & FHK & DOPD \\
\hline \multicolumn{7}{|c|}{ Labor Productivity - Emp. Share Weights } \\
\hline 1996 & 86.49 & 88.86 & 85.67 & 13.51 & 18.13 & 14.33 \\
\hline 1997 & 91.04 & 92.66 & 77.83 & 8.96 & 12.85 & 22.17 \\
\hline 1998 & 89.97 & 91.64 & 83.85 & 10.03 & 15.01 & 16.15 \\
\hline 1999 & 89.17 & 91.82 & 81.18 & 10.83 & 12.46 & 18.82 \\
\hline 2000 & 89.32 & 91.73 & 73.18 & 10.68 & 12.13 & 26.82 \\
\hline \multicolumn{7}{|c|}{ TFP - Value-added Share Weights } \\
\hline 1996 & 85.62 & 47.42 & 86.16 & 14.38 & -22.28 & 13.84 \\
\hline 1997 & 95.36 & 74.55 & 88.04 & 4.64 & -15.98 & 11.96 \\
\hline 1998 & 87.66 & 67.46 & 92.11 & 12.34 & -7.86 & 7.89 \\
\hline 1999 & 81.18 & 63.72 & 82.04 & 18.82 & -1.99 & 17.96 \\
\hline 2000 & 84.97 & 67.52 & 76.87 & 15.03 & -6.75 & 23.13 \\
\hline
\end{tabular}

Source: AJPES and own calculations.

Notes: The contributions of within-firm growth and between-firm reallocation are calculated as relative shares to the total contribution of surviving firms. FHK does not add up to 100 percent as the cross component is omitted.

under-measurement of the surviving firm contribution, we obtain an even larger gap for the overall contribution of this between-firm sub-component to Slovenian aggregate productivity growth. Over the 5 year interval from 1995-2000, we find that those market share reallocations towards more productive firms added 12 percentage points to aggregate labor productivity and 10 percentage points to aggregate TFP growth. These numbers are over double those given by the GR and FHK decompositions and represent a quarter of the overall productivity gains for Slovenian manufacturing.

\section{Conclusion}

In this paper, we proposed an extension of the productivity decomposition method developed by Olley \& Pakes (1996). This extension provides an accounting for the contributions of both entry and exit to aggregate productivity changes; and it also breaks down the separate contributions of firm-level productivity shifts and market share reallocations among surviving firms. We argue that the other decompositions that break-down aggregate productivity changes into these same four components introduce some biases in the measurement of the contributions of entry and exit. 
Furthermore, our proposed decomposition also inherits the attractive properties of the original Olley \& Pakes (1996) decomposition that aligns more directly the measured components of aggregate productivity changes within the framework of recent theoretical models featuring heterogeneous firms. We apply our proposed decomposition to the large measured increases of productivity in Slovenian manufacturing during the 1995-2000 period, accounting for the separate contributions of firm-level productivity changes, market share reallocations, entry, and exit. We contrast our results with those obtained from the other commonly used decompositions that break-down productivity changes into the same four components. Our results highlight that the magnitudes of the measurement bias relative to those other methods can be substantial over a five year period. In contrast to those other decompositions, we also find that market share reallocations among surviving firms played a much more important role in driving aggregate productivity changes.

In this paper, we have focused on decompositions at the firm-level, which is the finest level of aggregation in our data. However, our decomposition can also be applied at higher levels of aggregation. For example, the unweighted mean-covariance decomposition can be applied to industries as well. This generates a break-down of aggregate productivity into within- and inter-industry components. So long as firms do not switch their industry affiliation, our firm-level decomposition can be nested within the industry level decomposition. There are many other interesting groups of firms to which this decomposition method can be applied.

\section{References}

[1] Baily, M., Hulten, C., and Campbell, D. (1992). Productivity dynamics in manufacturing plants. In Brookings Papers on Economic Activity: Microeconomics, Vol. 4, pp. 187-267. Brookings Institute.

[2] Bartelsman, E., J.C. Haltiwanger and Scarpetta, S. (2013). Cross-Country Differences in Productivity: The Role of Allocation and Selection, American Economic Review 103 (1), 30534.

[3] Collard-Wexler, A., Asker, J. and De Loecker, J. Productivity Volatility and the Misallocation of Resources in Developing Economies, NBER Working Paper 17175.

[4] Foster, L., Haltiwanger, J.C., and Krizan, C.J. (2001). Aggregate Productivity Growth: Lessons from Microeconomic Evidence. in New Developments in Productivity Analysis. University of Chicago Press.

[5] Foster, L., Haltiwanger, J.C., and Syverson, C. (2008). Reallocation, Firm Turnover and Efficiency: Selection on Productivity or Profitability? American Economic Review, 98(1), pp. 394-425. 
[6] Hsieh, C.T., and Klenow, P.J. (2009): Misallocation and Manufacturing TFP in China and India, Quarterly Journal of Economics, 124(4), 1403-1448.

[7] Hopenhayn, H. A. (1992). Entry, Exit, and Firm Dynamics in Long Run Equilibrium. Econometrica, 60(5), pp. 1127-1150.

[8] Griliches, Z. and Regev, H. (1995). Firm productivity in Israeli Industry: 1979-1988. Journal of Econometrics, 65, pp. 175-203.

[9] Olley, S. and Pakes, A. (1996) The Dynamics of Productivity in the Telecommunications Industry. Econometrica, 64(6), pp. 1263-1298.

[10] Petrin, A. and Levinsohn, J. (2012). Measuring Aggregate Productivity Growth Using Plantlevel Data, RAND Journal of Economics, 43 (4), pp. 70525.

[11] Polanec, S. (2004) "On the Evolution of the Size and Productivity: Evidence from Slovenian Manufacturing," LICOS Discussion Paper No. 153, October. 


\section{Appendix}

\section{A Alternative Decomposition of Firm Productivity in Levels}

In the main text, we developed a decomposition of aggregate productivity as a weighted average of firm productivity measured in logs. Although this is typically the aggregate productivity measure that is reported and decomposed in the literature, it suffers from one potential drawback: it does not directly correspond to a measure that is relevant for aggregate welfare (see Petrin and Levinsohn, 2012, for a further discussion of this topic). Alternatively, one can define aggregate productivity as the weighted average of firm productivity in levels. This aggregate variable has a direct welfarerelevant interpretation, as it captures the economy's output per unit input (aggregate value added per worker in our example with labor productivity).

In this appendix, we show how our decomposition can be applied to this case. The only required modification relates to the covariance measure: we need to define a scale-independent covariance measure that is invariant to proportional changes in measured productivity. Such a measure is obtained simply by dividing firm productivity by aggregate productivity. Our scale independent measure is defined as $\widetilde{\operatorname{cov}}=\operatorname{cov}(s, \varphi / \Phi)=\operatorname{cov}(s, \varphi) / \Phi$. As with the covariance used in the main text with productivity measured in logs, $\widetilde{\operatorname{cov}}$ represents the share of aggregate productivity $\Phi$ that is driven by the correlation between productivity and market share; the remaining share $\bar{\varphi} / \Phi$ represents the contribution of the productivity distribution - independent of its correlation with market shares.

Using this scale-independent covariance, we can express the relative change in aggregate productivity as:

$$
\begin{aligned}
\frac{\Phi_{2}-\Phi_{1}}{\bar{\Phi}} & =\frac{\Phi_{S 2}-\Phi_{S 1}}{\bar{\Phi}}+s_{E 2} \frac{\Phi_{E 2}-\Phi_{S 2}}{\bar{\Phi}}+s_{X 1} \frac{\Phi_{S 1}-\Phi_{X 1}}{\bar{\Phi}} \\
& =\frac{1}{1-\overline{\widetilde{c o v}}_{S}} \frac{\bar{\Phi}_{S}}{\bar{\Phi}}\left(\frac{\Delta \bar{\varphi}_{S}}{\bar{\Phi}_{S}}+\Delta \widetilde{\operatorname{cov}}_{S}\right)+s_{E 2} \frac{\Phi_{E 2}-\Phi_{S 2}}{\bar{\Phi}}+s_{X 1} \frac{\Phi_{S 1}-\Phi_{X 1}}{\bar{\Phi}}
\end{aligned}
$$

where $\bar{\Phi}=1 / 2\left(\Phi_{1}+\Phi_{2}\right), \bar{\Phi}_{S}=1 / 2\left(\Phi_{S 1}+\Phi_{S 2}\right), \widetilde{\operatorname{cov}}_{S}=1 / 2\left(\widetilde{\operatorname{cov}}_{S 2}+\widetilde{\operatorname{cov}}_{S 1}\right)$ represent time averages over periods 1 and 2. By construction, $\widetilde{\operatorname{cov}}<1$ and hence $\widetilde{\widehat{c o v}}_{S}<1$. This alternate decomposition breaks-down aggregate productivity changes (now measured in levels) in a very similar way as the one we introduced in the main text (see (6)). The separation into the contribution of surviving, entering, and exiting firms in the first step proceeds in an identical fashion. We then separate out the contribution of the surviving firms into the same two components: one reflecting shifts in the 
distribution of firm productivity in levels via the change in the unweighted mean $\Delta \bar{\varphi}_{S}$ (withinfirm productivity changes), and the other reflecting the change in our scale-independent covariance measure (between-firm productivity changes). Unlike our original decomposition, these two terms require a common scaling factor so that they add up to the percentage change in the level of aggregate productivity. ${ }^{1}$

We report the results of this alternate decomposition in Table A.1 using the level of value added per worker and employment weights. This table is thus the counterpart to the DOPD columns in Tables 3 and 5. We see that the percentage changes in the level of aggregate productivity track the changes in the aggregate of log productivity quite closely, though the former are slightly below the latter by about one percentage point. However, the four separate components of this aggregate productivity change exhibit some larger deviations. Using productivity in levels leads to smaller contributions of exit and of within-firm productivity changes among surviving firms. On the other hand, this alternate decomposition of productivity changes in levels leads to a higher contribution of market share reallocations among surviving firms.

Table A.1: Dynamic Olley-Pakes Decomposition with Entry and Exit (Labor Productivity in Levels - Employment Share Weights)

\begin{tabular}{|c|c|c|c|c|c|c|}
\hline \multicolumn{7}{|c|}{ Aggregate Productivity Change Relative to 1995} \\
\hline \multirow[b]{3}{*}{ Year } & \multicolumn{3}{|c|}{ Surviving Firms } & \multirow{3}{*}{$\begin{array}{c}\text { Entering Firms } \\
s_{E 2} \frac{\Phi_{E 2}-\Phi_{S 2}}{\bar{\Phi}}\end{array}$} & \multirow{3}{*}{$\begin{array}{l}\text { Exiting Firms } \\
s_{X 1} \frac{\Phi_{S 1}-\Phi_{X 1}}{\bar{\Phi}}\end{array}$} & \multirow{3}{*}{$\begin{array}{c}\text { All Firms } \\
\begin{array}{c}\frac{\Phi_{2}-\Phi_{1}}{\bar{\Phi}}\end{array}\end{array}$} \\
\hline & \multirow[b]{2}{*}{$\frac{\Delta \bar{\Phi}_{S}}{\bar{\Phi}}$} & \multicolumn{2}{|c|}{ Share (in percent) } & & & \\
\hline & & $\begin{array}{c}\text { Within } \\
\frac{\Delta \bar{\varphi}_{S}}{\left(1-\widetilde{\overline{\operatorname{cov}}}_{S}\right) \Delta \bar{\Phi}_{S}}\end{array}$ & $\begin{array}{c}\text { Between } \\
\frac{\Delta \widetilde{\operatorname{cov}} \widetilde{\Phi}_{S}}{1-\widetilde{\overline{c o v}}_{S}} \frac{\bar{\Phi}_{S}}{\Delta \bar{\Phi}_{S}}\end{array}$ & & & \\
\hline$\overline{1996}$ & 13.22 & 49.70 & 50.30 & -1.66 & 2.00 & 13.56 \\
\hline 1997 & 28.95 & 59.45 & 40.55 & -2.30 & 3.48 & 30.13 \\
\hline 1998 & 31.48 & 75.70 & 24.30 & -2.58 & 4.17 & 33.07 \\
\hline 1999 & 40.62 & 70.88 & 29.12 & -2.41 & 4.02 & 42.23 \\
\hline 2000 & 46.19 & 64.45 & 35.55 & -1.95 & 4.42 & 48.66 \\
\hline
\end{tabular}

Source: AJPES and own calculations.

Notes: All values are given in percent.

\footnotetext{
${ }^{1}$ We can also further decompose the contributions of entry and exit in a similar way:

$$
\begin{aligned}
& \frac{\Phi_{S 1}-\Phi_{X 1}}{\bar{\Phi}}=\frac{1}{1-\overline{\widetilde{c o v}}_{1}} \frac{\Phi_{1}}{\bar{\Phi}}\left[\frac{\bar{\varphi}_{S 1}-\bar{\varphi}_{X 1}}{\Phi_{1}}+\left(\widetilde{\operatorname{cov}}_{S 1}-\widetilde{\operatorname{cov}}_{X 1}\right)\right] \\
& \frac{\Phi_{E 2}-\Phi_{S 2}}{\bar{\Phi}}=\frac{1}{1-\overline{\widetilde{c o v}}_{2}} \frac{\Phi_{2}}{\bar{\Phi}}\left[\frac{\bar{\varphi}_{E 2}-\bar{\varphi}_{S 2}}{\Phi_{2}}+\left(\widetilde{\operatorname{cov}}_{E 2}-\widetilde{\operatorname{cov}}_{S 2}\right)\right]
\end{aligned}
$$

where $\widetilde{\widetilde{c o v}}_{1}=s_{X 1} \widetilde{\operatorname{cov}}_{S 1}+\left(1-s_{X 1}\right) \widetilde{\operatorname{cov}}_{X 1}$ and $\widetilde{\operatorname{cov}}_{2}=s_{E 2} \widetilde{\operatorname{cov}}_{S 2}+\left(1-s_{E 2}\right) \widetilde{\operatorname{cov}}_{E 2}$
} 